\title{
A IMPORTÂNCIA DO TUTOR NO PROCESSO DE APRENDIZAGEM A DISTANCIA
}

\author{
Regina Barros Leal \\ Universidade de Fortaleza (UNIFOR), Brasil
}

\section{INTRODUÇÃO}

Há um debate em pauta no modelo de Educação a distancia -EAD em suas propostas mais atuais. A discussão posta nessa reflexão é contemporânea e se centra na necessidade do desvencilhamento de paradigmas cristalizados, no que se refere ao papel do Tutor no modelo de EAD com a inserção das novas tecnologias que vem exigindo mudanças paradigmáticas em sua estrutura didático-pedagógica. Nessa questão emerge um debate atual: o papel da tutoria na EAD e sua relevância no processo.

"O trabalho em programas de educação a distância permitiu-nos e permite-nos identificar algumas questões em torno das quais permanentemente colocam-se dúvidas e interrogações. O tutor - seu papel, suas funções, as tarefas que tem de realizar, as responsabilidades que assume é um desses pontos-chave nos quais costumam aparecer mais perguntas que respostas. O que significa ser tutor? Quais são os alcances da tarefa? Qual é a especificidade do seu papel? Há uma especificidade do seu papel? Quem é reconhecido como bom tutor? Como se forma um tutor? Como se avalia seu trabalho? O tutor é imprescindível na modalidade a distância? (MAGGIO,, 2001) ${ }^{1}$

Essas questões expressam as indagações presentes nos programas de educação a distancia, numa tentativa de redefinir as funções dos protagonistas da ação educativa, ressignificando os papeis dos atores principais, e em especial , o papel do tutor.

Quem seria então o Tutor? Um mestre? U m educador? Aquele que ultrapassaria a visão restrita do especialista, do conteudista ? Um educador que transcende o papel de motivador, de facilitador. Um educador que sustenta uma reflexão sobre a complexidade da ação educativa, mesmo a distancia,ultrapassando os modelos lineares ? Um Tutor que para organizar situações que promovam a aprendizagem dos alunos transgredi algumas normas já padronizadas e tão confiáveis?

Eis um desafio.

Na nossa concepção, ainda preliminar porquanto não se ter uma experiência consolidada em EAD, compreendemos o papel do Tutor enquanto categoria acadêmica, baseada no compromisso com a formação de alunos que pensem e sejam capazes de discutir e elaborar conhecimento. Um Tutor educador, que tenha percorrido um caminho que o leve ao pensar livre, descarnado de preceitos tecnológicos que obtusam as mentes criativas. Um Tutor que compreenda o papel da universidade,num contexto a distancia, como lócus do debate, da criação, que se permita desconstruir e reconstruir significados na sua ação formativa e na construção do saber cientifico. Um tutor/educador capaz de se indignar com a vulgaridade de propostas alienantes; capaz de elaborar um contra -discurso ideológico; que

\footnotetext{
${ }^{1}$ MAGGIO, Mariana, O Tutor na Educação a Distância, In: Educação a Distância: Temas para o debate de uma nova agenda Educativa, Edith Litwin, Organizadora, Porto Alegre, Artmed Editora, 2001
} 
sobretudo, seja aberto à mudanças, aos novos paradigmas tecnológicos. Enfim, um profissional com condições de aprender a aprender com competência para fazer da educação a distancia, um espaço de virtualidade criativa, poética, formativa e comprometidos com a formação de alunos críticos e sujeitos pensantes. Parece lugar comum, mas não nos parece ser exaustivo repetir essa questão, por ser por demais presente.

Nessa perspectiva de construção de saberes que se articulam no espaço virtual, o Tutor poderia ser aquele que instiga a participação do aluno evitando a desistência, o desalento, o desencanto pelo saber. Talvez aquele que possibilita a construção coletiva e percorre uma trajetória metodológica desobediente, transgressora de receitas prontas e acabadas e construa, de forma participativa com seus alunos nova saberes, novos olhares sobre o real.

No texto Educação de Adultos-Uma abordagem Andragógica, o autor (GOECKS ,2004) enfatiza que o facilitador preparado está consciente dos complexos processos sociais envolvidos na interação grupal e no processo criativo. Essa afirmação nos instiga a elaborar uma reflexão que percebo como sendo crucial, capital, para a EAD. Propiciar um diálogo entre alunos e Tutores, no contexto da EAD, uma conversação didática criativa e capaz de fomentar o pensamento, a liberdade do pensamento, a fluência das idéias, o confronto de posições epistemológicas. Precisamos ainda aprender a articular conhecimento, integrar saberes, porque ainda não superamos a forma disciplinar, fragmentada trabalhar o conhecimento. E onde fica a complexidade? A interdisciplinaridade? A transdisciplinariedade? Não seria então, o momento de criar uma categoria acadêmica do Tutor, articulado com o papel de educador que está em contato com o aluno na perspectiva da sua formação e no compromisso de interdisciplinar o conhecimento?

\section{O CABE REALMENTE AO TUTOR E QUAL SUA IMPORTÂNCIA?}

Cremos numa relação fundamentada numa concepção de participação, em que seu elemento fundante seja uma prática transformadora. Uma prática articulada com o diálogo e com orientações acadêmicas que gerem reflexões sobre a unidade do saber, a totalidade do conhecimento e a capacidade do sujeito aprendente criar e gerar conhecimento. Cremos no reencantamento da educação, na reconstrução de saberes, na articulação com o outro, daí entender que o espaço virtual, bem como as novas tecnologias da comunicação e informação podem ser interessantes no fazer educativo. Eu pergunto então/? Como desenvolver a educação hoje desconhecendo essa realidade? Como negar o inegável? Como se inserir na sociedade globalizada, na sociedade do conhecimento sem confundir o conhecimento com informação. Como ter a sensibilidade aguçada para sermos mais inteligentes na utilização da tecnologia sem perder de vista a nossa essencialidade humana. Como sermos sujeitos que constroem, que reconhecem a beleza do natural, do sol, da ternura de uma noite de luar e navegar no espaço virtual, usar as tecnologias sem nos aprisionar aos meios? Será então o nosso maior desafio não permitir que a tecnologia retire do aluno, em sua aprendizagem o contato com a estética do natural, com a beleza infinita das estrelas, com o efeito mágico do luar, com o encontro com o outro na relação EU e TU. Como desenvolver uma dimensão axiológica., ética na EAD? Recorremos a llich a "À medida que eu domino a ferramenta, eu preencho o mundo com sentido; à medida que a ferramenta me domina, ela me molda sua

${ }^{2}$ GOECKS, Rodrigo. Educação de Adultos - Uma Abordagem Andragógica. In: http://www.andragogia.com.brl . Acesso em 22/07/2004 
estrutura, e me impõe uma idéia de mim mesmo"3 A reflexão sobre essa questão é fundamental para nossa liberdade de criar e pensar sobre o mundo.

Trabalhar a complexidade do saber fazer educativo na visão do aprender a aprender, na ótica reflexiva da construção do saber é um dos grandes desafios do Tutor. Ainda, propiciar momentos em que o aluno aprenda a ler e a reler o mundo, a apropriar-se do conhecimento, a redimensionar valores, a rever atitudes.

Lembremos uma frase de Jean Piaget: "Os fenômenos humanos são biológicos em suas raízes, sociais em seus fins e mentais em seus meios". A experiência humana é um todo bio-psico-social, que não pode ser dividido em partes nem reduzido a nenhuma delas. Primeiro, percebemos o mundo. Em seguida, as percepções geram sentimentos e emoções. Na seqüência, estes são elaborados em forma de pensamentos, que vão determinar o nosso comportamento no cotidiano ${ }^{4}$

Os múltiplos fatores nos acercam e se não formos curiosos e ousados para descobrir suas vantagens e possibilidades, certamente que ficaremos obsoletos e ultrapassados. Não seremos homens do tempo de hoje. E como nos adaptar a realidade que muda a cada instante e aprendermos a lidar com as nossas resistências, face ao nosso tempo cultural, social? Arriscando, arrojando-se, com a mente aberta para o novo, porque é por ai que aprendemos a ressignificar conceitos, a transversalizar o conhecimento, sem perder de vista a hominização. ;E é possível na EAD?

O papel do tutor então, na nossa perspectiva, ultrapassa a visão puramente técnica, transcende a exacerbação da especialidade, adquirindo competência para instrumentalizar a tecnologia. $O$ papel do Tutor, sobremodo, supera assim o conceito reducionista de propostas estritamente técnicas. O Tutor é um educador a distancia. Aquele que coordena a seleção de conteúdos, que discute as estratégias de aprendizagem, que suscita a criação de percursos acadêmicos, que problematiza o conhecimento, que estabelece o diálogo com o aluno, que media problemas de aprendizagem, sugere, instiga, acolhe. Enfim, um professor no espaço virtual, exercendo a sua função de formar o aluno.

Como desenvolver na EAD um papel reflexivo? Não há respostas prontas, acabadas, mas a convicção de que educar, mesmo a distancia, é um movimento para formação do aluno, onde a dimensão de possibilidades permeia a ação educativa. Se não entendermos esse paradigma do contra discurso técnico, se não transgredirmos os modelos cristalizados em fórmulas tecnológicas, que colocam os sujeitos como respondentes passivos do processo, estaremos reproduzindo uma educação tecnicista, alienada.Assim ratifico a importância vital de um Tutor com formação acadêmica que organize situações didáticas, juntamente com os alunos, escapando das armadilhas técnicas. Uma ação tutorial que procure desvelar as subjetividades presentes na construção de saberes dos sujeitos envolvidos.

Pergunta-se : Será possível ultrapassar as limitações e alcançar tais possibilidades na EAD? Lembramos que a seriação tolda a diversidade. Como evitar sobretudo, a padronização perseverando na busca de respostas criativas? Defendemos uma concepção de que o Tutor seria aquele que, problematizando o conhecimento crie estratégias em que o do aluno veja o mundo e a si mesmo e

\footnotetext{
${ }^{3}$ ILLICH, Ivan. A Convivencialidade. Lisboa: Europa-América, 1976.

${ }^{4}$ Resumo elaborado por JulioTôrres, do texto de Complexidade e Pensamento Sistêmico de Humberto Mariotti em 2004. Grupo de estudo sobre Complexidade da UNIFOR
} 
vislumbre os riscos, as incertezas, a temporalidade humana, as vantagens da tecnologia, do conhecimento e o encantamento do aprender. Além disso, aprenda a usar a tecnologia, a adquirir competência e habilidades no trato de questões de natureza técnica e operacional. Um Tutor que procure garantir a relação teoria e prática; a investigação do real no desenvolvimentos de situações de aprendizagem.

\section{QUAL SERIA A SUA FORMAÇÃO DO TUTOR?}

A nosso juízo, o Tutor teria uma formação acadêmica definida por sua experiência em educação, sua titulação acadêmica, seu conhecimento didático-pedagógico. Talvez seja imprescindível que tenha experiência no ensino presencial. Quem sabe, assim poderia compreender a diversidade dos sujeitos e a complexidade e singularidade do processo de aprendizagem e as diferentes teorias. Além desse perfil, um Tutor teria que entender o encantamento do processo de aprendizagem para se apaixonar por sua atividade docente, principalmente pela distancia real de contatos presenciais. EAD não se limita a um processo informativo.

Toda e qualquer experiência pedagógica não prescinde de um processo metodológico que a coloca em movimento, ao qual subjaz uma concepção que se objetiva em um plano, um método, porém, não se reduz a ele (ao processo metodológico). O que garante a qualidade de um processo de trabalho de caráter pedagógico é a congruência entre seus elementos: concepção, conhecimento específico e organização didático-metodológica. ${ }^{5}$

Entretanto, pensamos que é importante refletir e discutir mais profundamente sobre o método, as estratégias que conduzem ao debate criativo. Essa questão também nos remete ao conceito de Poiesis ${ }^{6}$ como ato criativo (mesma raiz de "poesia"); a vida é autopoiética, ela cria, ela inventa e reinventa a si própria - a partir de si própria.. Alguém poderia perguntar: Mas o que tem isso a ver com EAD? Eu diria, sem me arvorar de nenhuma certeza, talvez esse seja uma reflexão necessária para que não perdermos de vista os caminhos para reinvenção.

Mas vejamos,

Qual é , em essência, na visão acadêmica, o papel do Tutor ? Seria um Tutor/ professor/andragogo com competência para organizar pesquisas criativas, situações provocativas do ato criador nesse universo de possibilidades que é a EAD. Muitas são as denominações. Mas, a todo custo devemos evitar a formação de um Tutor que reproduza a fragmentação do saber, a cultura de lotes de conhecimento. É fundamentar garantirmos uma formação que sustente a compreensão da prática educativa em que seus elementos fundantes se inspirem numa concepção do belo, da unicidade, da estética, das possibilidades circunscritas na relação educador- educando baseada no diálogo, no encontro com o outro. Por ser diferente ensino a distancia exige habilidades diferenciadas, principalmente com a introdução de novas tecnologias. É um sistema peculiar de educação., daí a necessidade de uma sólida formação acadêmica.

E sobre a relação tutor- aluno ? Ambos são protagonistas. Uma proposta de ensino que estabeleçam, em seu cerne, uma separação entre educador educando já indica um caminho autoritário, linear. Daí, o desafio permanente da EAD.

\footnotetext{
${ }^{5}$ CATAPAN, Araci Hack FIALHO, Francisco Antonio Pereira.Autonomia e Sensibilidade na rede: uma proposta metodológica..2004R

${ }^{6}$.Poiesis é o ato criativo (mesma raiz de "poesia")
} 
Chamamos atenção para uma reflexão que nos parece interessante. Não seria cabível discutirmos outro paradigma.? Pensarmos em um modelo de EAD que contemplasse o papel do Tutor como um professor, que mesmo a distancia não estivesse distante dos seus alunos. Um Tutor presente no processo,: relatando experiências, conferenciando, orientando leituras, pesquisas, compartilhando com os alunos estratégias de ensino, escolhendo com alunos material de pesquisa, temas para debates no forun, construindo conhecimento. Entretanto os tutores teriam monitores. Alunos que podem assumir algumas atividades a distancia, que colaborassem com o Tutor e, nesse contexto, as escolhas, a os diálogos entre alunos e monitores e Tutor fortaleceria, quem sabe, a atividade acadêmica. Juntos, tutores, monitores e alunos, poderiam apresentar sugestões temáticas, metodológicas e operacionais no sentido de fortalecer o processo participativo.

Nesse modelo poderíamos criar uma forte motivação para os alunos que expressassem interesse na EAD e estaríamos preparando, ao longo do processo, futuros tutores. Seria um modelo similar ao sistema de monitoria da universidade no ensino presencial.

Enfim, as questões expressas no texto refletem a nossa preocupação com relação à formação do Tutor. Foi nossa intenção instigar reflexões mesmo que também estejam presentes no ensino presencial. Nossa crença é que a EAD, é diferenciada em seus meios, mas não se desvencilha, em sua essência, das dimensões presentes no processo educativo. Dessa forma, reafirmamos que "a pedagogia de possibilidades cria um espaço fecundo, porque é trabalhando com as possibilidades que revelamos nossa crença nas pessoas, no potencial criativo (LEAL, 1997)

\section{BIBLIOGRAFIA}

CatAPAN, Araci Hack FIAlHo, Francisco Antonio Pereira.Autonomia e Sensibilidade na Rede: uma proposta metodológica. .2004

GOECKS, Rodrigo. Educação de Adultos - Uma Abordagem Andragógica. In: http://www.andragogia.com.br/ . Acesso em 22/07/2004

ILLICH, Ivan. A Convivencialidade. Lisboa: Europa-América, 1976.

LEAL, Regina Barros. Proposta Pedagógica para Adolescente Privado de liberdade. Ceará, UNICEF, 1998

MAGGIO, Mariana, O Tutor na Educação a Distância, In: Educação a Distância: Temas para o debate de uma nova agenda Educativa, Edith Litwin, Organizadora, Porto Alegre, Artmed Editora, 2001 


\title{
Contactar
}

Revista lberoamericana de Educación

\author{
Principal OEI
}

